\title{
Detour problem-solving behavior in rats with neocortical and hippocampal lesions: A study of response flexibility
}

\author{
ROBERT THOMPSON, DAVID HARMON, and JEN YU \\ Fairview State Hospital, Costa Mesa, California \\ and University of California Irvine Medical Center, Orange, California
}

\begin{abstract}
Young rats previously subjected to discrete neocortical ablations or hippocampal electrolytic lesions received five trials on each of three "climbing" detour problems. Performance on Trial 1 (a measure of response flexibility) of each problem was significantly impaired in those groups with frontal, parietal, or hippocampal lesions; the group with occipital lesions was impaired on only one problem. Performance on Trials 2-5 (a measure of detour habit formation) of each problem was significantly impaired only in the hippocampal group; the neocortical groups showed either no impairment or a mild impairment on these trials. These results suggest that the solution of detour problems on the first trial may require a cognitive process that is qualitatively different from that required on subsequent trials.
\end{abstract}

One of the features of adaptive (intelligent) behavior is "the ability rapidly to discard unsuccessful responses and to attempt new ones, until the correct one is found"' (Riopelle, 1967, p. 253). This ability, which can be called "response flexibility," has not usually been the focus of experiments aimed at investigating the cognitive functions of brain-damaged animals. While such learning tasks as spatial reversal and passive avoidance do require the replacement of one type of reaction with another, they can hardly be viewed as satisfactory tests of response flexibility, not only because the number of alternative responses is generally limited to one (approach the left alley rather than the right one or simply withhold an approach response altogether), but because the alternative responses have a high probability of being performed once the prepotent response is no longer rewarded.

A laboratory situation that is amenable to the study of response flexibility involves the classical "umweg" or "detour" problem which was first systematically investigated by Kohler (1927). In this situation, the direct pathway to the goal object is blocked, and the subject is required to find an alternate pathway (or remove the barrier or even use a tool) in order to gain access to the goal object. While the detour problem has many variations, its essence lies in the fact that the correct response is not one that the subject immediately attempts in the situa-

The completion of this study was facilitated by a grant from the Rehabilitation Center for Brain Dysfunction, Irvine, California. The authors are affiliated with the Department of Physical Medicine and Rehabilitation of the University of California Irvine Medical Center. Requests for reprints should be sent to Robert Thompson, Fairview State Hospital, 2501 Harbor Boulevard, Costa Mesa, CA 92626. tion-it is relatively low on the habit-family hierarchy, in the language of Hull (1952).

As far as can be determined, only one study has been reported which specifically examined the effects of brain damage on the performance of a detour problem (Krechevsky, 1938). The problem involved a choice between an efficient indirect (detour) route and a less efficient direct route to a reward. It was found that rats with neocortical lesions (averaging about $19 \%$ of the total neocortical surface), in contrast to the controls, failed to adopt the detour solution in spite of extensive training. Interestingly, the deficit was found to be independent of the locus of the lesions, but no "mass action" effect was obtained.

Some of the latchbox tasks designed by Lashley (1935) can be viewed roughly as detour problems to the extent that responses of relatively low probability were required to open a locked door leading to a reward (e.g., pressing a lever, tearing a strip of paper, pulling a chain, or pulling a handle). Neocortically damaged rats (sustaining an average of about $26 \%$ destruction to the neopallial surface) were found to be impaired in learning most of these problems, and there was some evidence that the extent of the impairment was proportional to the magnitude of the lesions and independent of their locus. With regard to the behavior of the brain-damaged rats, Lashley (1935) noted that "their reactions to various objects in the problem situation lack the variety and adaptive character of the behavior of the normal animal" (pp. 32-33). This observation, of course, suggests that the cortically injured rat shows a reduction in response flexibility. Nonetheless, it would be of interest to determine whether the cortically lesioned rat would be deficient in response flexibility when confronted with other types of detour problems. 
It is important to note that performance on the first trial of a detour problem provides the purest measure of response flexibility, inasmuch as performance on subsequent trials is contaminated by the memory of the correct and incorrect responses made on the first trial. In other words, the solution of a detour problem on the first trial may require a cognitive process that is qualitatively, or at least quantitatively, different from that required on later trials. If this is, indeed, the case, then it is possible that the brain mechanisms responsible for the appearance of the correct response on the first trial may be dissociated, at least in part, from those responsible for the reappearance of the correct response on succeeding trials. One likely example of this might be a given brain-damaged group of rats that is impaired in solving a particular detour problem on the first trial, but is unimpaired on subsequent trials.

Finally, it should be apparent that the rapid solution of detour problems would be critically dependent both upon normal exploratory tendencies (identifying the presence of novel objects and/or the rearrangement of familiar objects to which investigatory responses can be made) and intact immediate ("working") memory (remembering previously attempted unsuccessful responses). The hippocampus is one of the brain structures that has been implicated in each of these psychological processes (O'Keefe \& Nadel, 1978; Olton \& Papas, 1979) and, as a consequence, should be selected for study along with the neocortex.

In light of the foregoing considerations, the present work was undertaken to assess the effects of neocortical and hippocampal lesions on the solution of three different "climbing" detour problems. Although five trials were given on each problem, performance on Trial 1 (involving the initial discovery of the correct detour response) was considered to be the most effective measure of response flexibility. Performance on Trials 2-5, on the other hand, may be viewed as a measure of the formation of the habit.

\section{METHOD}

\section{Subjects and Surgery}

Weanling (21-23-day-old) male Sprague-Dawley albino rats, 40-60 g, underwent surgery under deep chloral hydrate anesthesia $(400 \mathrm{mg} / \mathrm{kg})$. Three groups sustained bilateral aspirative ablations of the occipital cortex (Group O), parietal cortex (Group P), or frontal (motor) cortex (Group F). A fourth group (Group H) received bilateral electrolytic lesions to the dorsal hippocampus. The last group, consisting of the controls (Group C), underwent the same surgical procedures as Group $\mathrm{H}$, except for the insertion of the lesion electrode and the application of current.

Throughout the recovery period, the animals were housed, two or three per cage, in medium size wire cages containing a constant supply of food pellets and water and were handled for approximately $3 \mathrm{~min}$ on every $3 \mathrm{rd}$ day. Both preoperatively and postoperatively, a dish of sweetened wet mash was periodically placed in the home cages.

\section{Apparatus}

The test apparatus, made almost entirely of plywood, was divided into a startbox $(22.8 \times 23.0 \times 30.3 \mathrm{~cm})$ painted flat white, a choice chamber $(61.6 \times 56.8 \times 30.3 \mathrm{~cm})$ painted flat white, and a goalbox $(30.1 \times 56.8 \times 30.3 \mathrm{~cm})$ painted flat black. A clear Plexiglas guillotine door separated the startbox from the choice chamber. Interchangeable partitions could be inserted, in conjunction with a platform, a cylinder, or a ladder (each of which was painted flat white), between the choice chamber and goalbox to form the various detour problems. During preliminary training, a partition containing a centrally located window $(10.4 \times 10.0 \mathrm{~cm})$ at floor level was used. For Problem A, the partition used in preliminary training was placed in the apparatus along with a platform (38.2 $\times 58.8 \mathrm{~cm}$ ) that sloped upwards into the choice chamber to a maximum height of $10.1 \mathrm{~cm}$ (see Figure 1A). Problem B consisted of a partition containing a centrally located plastic cylinder $(4.6 \mathrm{~cm}$ in diameter) that extended $20.3 \mathrm{~cm}$ into the choice chamber and was elevated $5.7 \mathrm{~cm}$ above the floor (Figure 1B). Problem C consisted of a partition containing a window $(10.5 \times 7.7 \mathrm{~cm})$ located $10.3 \mathrm{~cm}$ above the floor that could be reached only by climbing a ladder $(20.9 \times 7.7 \mathrm{~cm}$ with rungs spaced $2.0 \mathrm{~cm}$ apart $)$ that extended $19.2 \mathrm{~cm}$ into the choice chamber (Figure 1C). The entire apparatus was covered by a transparent Plexiglas sheet and was illuminated by conventional ceiling fluorescent lights.

Activity was measured in a $56.0 \times 224 \mathrm{~cm}$ open field enclosed on three sides by the walls of the room and on the fourth side by a 32.5-cm-high partition. The floor of the field was divided into $1628.0-\mathrm{cm}$ squares. Lighting was provided by conventional ceiling fluorescent lights.

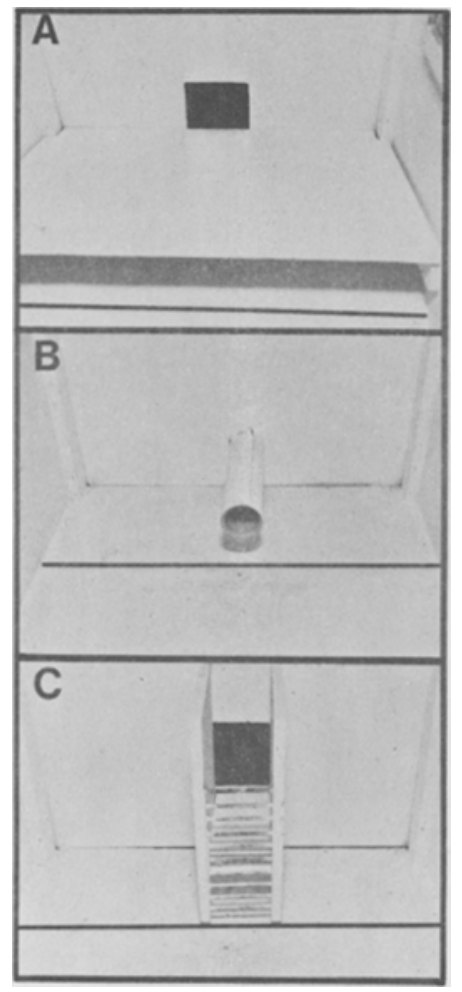

Figure 1. Photographs of the choice chamber showing the detour paths for each problem. The thin lines mark the boundaries of the "blind alleys." On Problem A, the rat must clinb onto the raised platform to reach the goalbox. On Problem B, the rat must enter the cylinder to reach the goslbox. On Problem $C$, the rat must climb the ladder to reach the goalbox. 


\section{Procedure}

\section{Preliminary Training}

Following a 3-week recovery period, the animals were weighed and then deprived of water in their home cages for the duration of the learning experiment. After 2 days of deprivation, each animal was allowed to explore the entire apparatus (Day 1). In the goalbox, a dish of water as well as a dish of sweetened wet mash were available from which the animal was permitted to ingest for 10 min. On Day 2, the animals (usually run in squads of two or three) were given 10 preliminary training trials with an intertrial interval of 90-180 sec. Each trial was begun by placing the animal in the startbox and raising the startbox door. In most instances, the animal would readily leave the startbox, traverse the choice chamber, enter the goalbox through the centrally located window, and ingest the water and/or mash. After $10 \mathrm{sec}$, the animal was transferred to a restraining cage to await the next trial. On the 10th trial, most of the animals were allowed to ingest the water and mash for approximately $200 \mathrm{sec}$. (This period, however, was reduced by at least $50 \%$ in those animals that were consistently reluctant to leave the startbox, slow in traversing the choice chamber, or hesitant in ingesting the water and mash during the course of preliminary training.)

\section{Detour Training}

Problem A was introduced on Day 3, Problem B on Day 4, and Problem C on Day 5. Five trials were given on each problem, with an intertrial interval of approximately $90-300 \mathrm{sec}$. The training procedure was the same as that described for preliminary training, except that this time response latencies-time between when the startbox door was raised and when the rat entered (all four legs placed beyond the threshold) the choice chamber-were recorded.

With respect to Problem A, an error was counted when a rat passed under the raised platform by at least the length of the animal's body (excluding the tail). For Problem B, an error was counted when a rat traversed beyond the opening of the elevated cylinder by at least the length of the animal's body. An error on Problem $C$ was counted when the rat traversed beyond the ladder by at least the length of the animal's body. (See Figure 1 for further details.) Total (initial combined with repetitive) errors were recorded on each trial.

If an animal committed a total of 20 errors on Trial 1, 15 errors on Trial 2, 10 errors on Trial 3, or 5 errors on Trial 4 or Trial 5, it was assisted manually in mounting the platform (Problem A), entering the cylinder (Problem B), or climbing the ladder (Problem C). This was done in order to prevent the onset of "learned helplessness." However, the error score reached at the point of assistance was treated as though the animal had succeeded in solving the problem on that trial.

Finally, if an animal exhibited very little exploratory behavior on Trial 1 of Problem A (at least 5 min elapsing between the commission of one error and the next), it was discarded from the experiment. During training, the experimenter had no knowledge of which group each subject belonged to.

\section{Open-Field Activity}

After completing training on Problem $C$, the animals were placed on ad-lib food and water. Twenty-four hours later (Day 6), each animal was placed in the center of the open field and allowed to explore during a $10-\mathrm{min}$ period. The number of squares entered by all four paws was recorded. The number of rears made was also counted. A rear was recorded only when the animal stretched upward to the extent of removing its forepaws from the floor.

\section{Histology}

After the activity test, each brain-damaged animal was killed with an overdose of chloral hydrate, its vascular system perfused with normal saline followed by $10 \%$ Formalin, and the brain removed and stored in $10 \%$ Formalin for $2-4$ days. The cortical lesions were reconstructed on Lashley-type brain diagrams, from which the percentage of neocortical destruction was determined by a procedure similar to that described by Lashley (1929). Each brain was then blocked, frozen, and sectioned frontally at $90 \mu$. Every fourth section through the lesion was retained and subsequently photographed at $12 \times$ by using the section as a negative film in an enlarger (see Thompson, 1978a).

\section{RESULTS}

\section{Discarded Subjects}

Eight animals were discarded from the experiment because they showed little exploratory behavior (probably due to timidity) in the choice chamber on Trial 1 of Problem A. Five came from Group O, one from Group $\mathrm{C}$, one from Group $\mathrm{H}$, and one from Group P. The data derived from these animals were not included in any of the analyses to follow.

\section{Histology}

Figure 2 shows the smallest and largest lesions sustained by the cortically damaged groups. The extent of damage to the entire neocortical surface averaged $19.0 \%$ (range $=16 \%-23 \%$ ) in Group F, $23.1 \%$ (range $=18 \%-29 \%$ ) in Group $P$, and $26.1 \%$ (range $=20 \%-34 \%$ ) in Group $O$. Damage to underlying
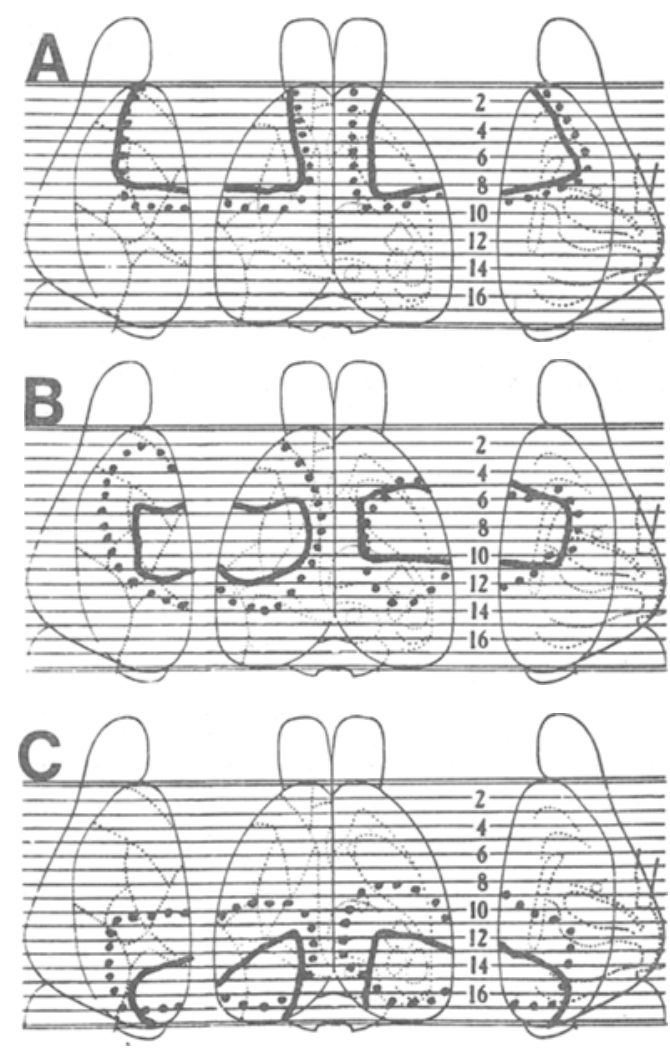

Figure 2. Diagrams showing the largest (areas enclosed by heavy dotted lines) and smallest (areas enclosed by heavy solid lines) lesions to the frontal (A), parietal (B), and occipital (C) regions. 
structures, such as the caudoputamen and hippocampus, was either absent or minimal.

Figure 3 shows a representative lesion to the dorsal hippocampus. In the majority of cases, superficial injury to the subjacent thalamus was observed. (Animals with thalamic damage, however, were not found to differ appreciably from those without thalamic damage in terms of any of the behavioral measures recorded in this study.)

\section{Body Weight}

After a 3-week recovery period, the mean body weights ( \pm standard errors) of Groups C, F, P, O, and $\mathrm{H}$ were $137.3 \pm 6.9 \mathrm{~g}, 119.9 \pm 5.2 \mathrm{~g}, 138.4 \pm 6.2 \mathrm{~g}$, $136.4 \pm 5.9 \mathrm{~g}$, and $132.0 \pm 6.1 \mathrm{~g}$, respectively. None of the intergroup differences was statistically significant. (Unless specified otherwise, the Mann-Whitney two-tailed test was used for all comparisons in this study.)

\section{Detour Performance}

\section{Error Scores}

Control group. With respect to Trial 1, Group C averaged fewer than 6 errors on each of the three detour problems (see Table 1). Only one animal required

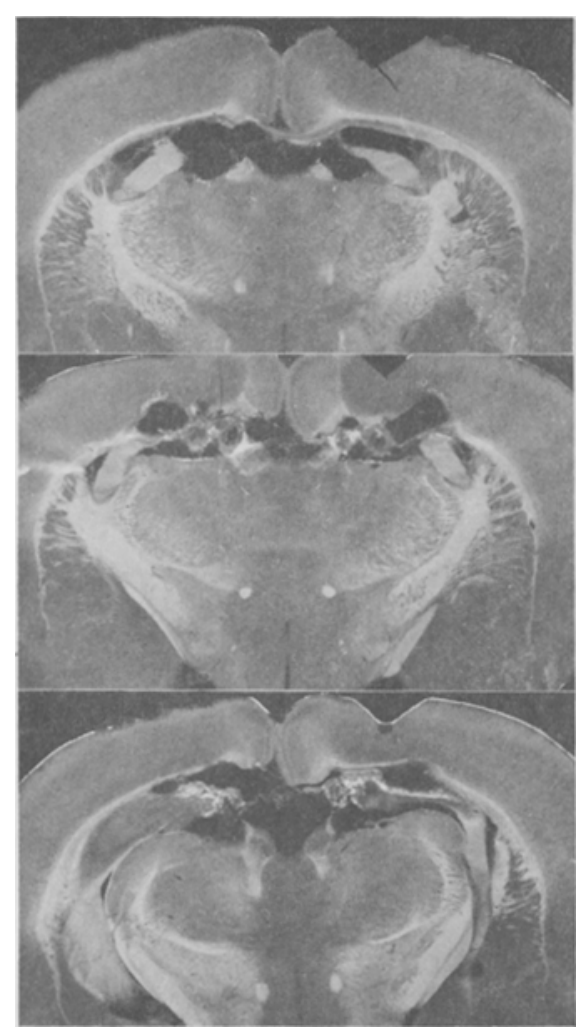

Figure 3. Photographs of unstained sections showing a typical lesion to the dorsal hippocampus. assistance (committing 20 errors), and that was on Prob'em B. Although Problem A tended to be the most difficult and Problem $C$ the least difficult to solve, the Wilcoxon test revealed that none of the differences in error scores approached statistical significance.

With respect to Trials 2-5 (see Table 1), fewer errors were committed on Problem $\mathrm{C}$ than on Problem A $(p<.05)$ or Problem B $(p<.01)$, but the difference in error scores between the latter two problems was not significant.

These results, suggesting that Problem $C$ was easier to master than Problems A or B, must be viewed with caution, since the order of presentation of the problems was not counterbalanced.

Cortically damaged groups. It will be observed in Table 1 that Groups $F$ and $P$ made significantly more errors on Trial 1 of each problem than did the controls. Group $\mathrm{O}$, however was significantly inferior to the controls only on Problem B. Five cortically damaged rats needed assistance (committing 20 errors) on Problem $A$ (four from Group $F$ and one from Group P), eight on Problem B (two from Group F, three from Group P, and three from Group $O$ ), and four on Problem C (three from Group F and one from Group P).

With respect to Trials $2-5$, the difference in error scores between each cortically damaged group and the controls on Problem A was not significant. On Problem B, only Groups $\mathbf{P}$ and $\mathrm{O}$ made significantly more errors than the controls, but all cortically damaged groups were significantly inferior to the controls on Problem C.

It would appear from the foregoing analysis that the frontal and parietal cortices are more important than the occipital cortex for the rapid solution of detour problems. This was further shown by the finding that Groups $\mathbf{F}$ and $\mathbf{P}$ made more pooled errors (errors summed over all three problems) than did Group O on Trial 1 (ps $<.05$ ) as well as on Trials 2-5 (ps $<.05$ ).

Although performance on Trial 1 of each problem tended to be affected by the presence of cortical (particularly frontal and parietal) damage, there were several instances in which performance on Trials 2-5 was not affected by the presence of these lesions (see Table 1). Inspection of Figure 4 further attests to the findings that the most conspicuous difference between the controls and the cortically injured animals appears on Trial 1.

Lesion size does not appear to contribute to the foregoing pattern of observations. The rank-order correlation between pooled errors on Trial 1 and the extent of cortical damage for all 31 subjects was computed to be -.10 . A similarly small and insignificant correlation of +.04 was computed between pooled errors on Trials 2-5 and the magnitude of cortical damage. 
Table 1

Mean Errors and Mean Response Latencies (in Seconds) on Each Problem for All Groups

\begin{tabular}{|c|c|c|c|c|c|c|c|c|c|c|}
\hline \multirow[b]{3}{*}{ Group } & \multirow[b]{3}{*}{$\mathbf{N}$} & \multicolumn{3}{|c|}{ Problem A } & \multicolumn{3}{|c|}{ Problem B } & \multicolumn{3}{|c|}{ Problem C } \\
\hline & & \multicolumn{2}{|c|}{ Errors } & \multirow{2}{*}{$\begin{array}{l}\text { Response } \\
\text { Latency }\end{array}$} & \multicolumn{2}{|c|}{ Errors } & \multirow{2}{*}{$\begin{array}{l}\text { Response } \\
\text { Latency }\end{array}$} & \multicolumn{2}{|c|}{ Errors } & \multirow{2}{*}{$\begin{array}{c}\text { Response } \\
\text { Latency }\end{array}$} \\
\hline & & Trial 1 & Trials 2-5 & & Trial 1 & Trials 2-5 & & Trial 1 & Trials $2-5$ & \\
\hline $\mathrm{C}$ & 13 & $5.4 \pm .6$ & $2.5 \pm .4$ & $3.3 \pm 1.6$ & $5.2 \pm 1.7$ & $2.8 \pm .6$ & $2.5 \pm .4$ & $4.5 \pm .8$ & $.7 \pm .2$ & $1.5 \pm .2$ \\
\hline $\mathrm{F}$ & 11 & $14.5 \pm 1.8^{*}$ & $3.1 \pm .9$ & $3.2 \pm .4$ & $10.6 \pm 2.1 *$ & $4.7 \pm 1.2$ & $3.7 \pm .5$ & $12.7 \pm 1.7^{*}$ & $4.6 \pm 1.2^{*}$ & $2.7 \pm .1 *$ \\
\hline$P$ & 10 & $12.0 \pm 1.7 *$ & $2.2 \pm .4$ & $5.6 \pm 2.1$ & $9.9+2.2^{*}$ & $6.7 \pm 1.4^{*}$ & $6.4 \pm 3.4$ & $8.5 \pm 1.6 *$ & $4.3 \pm .8 *$ & $2.8 \pm .4^{*}$ \\
\hline $\mathrm{O}$ & 10 & $5.6 \pm 1.1$ & $1.5 \pm .2$ & $3.6 \pm .9$ & $13.5 \pm 1.5^{*}$ & $3.3 \pm .6$ & $4.1 \pm .5^{*}$ & $6.3 \pm 1.3$ & $2.3 \pm .6^{*}$ & $2.0 \pm .3$ \\
\hline $\mathbf{H}$ & 10 & $15.6 \pm 1.9^{*}$ & $15.5 \pm 4.5^{*}$ & $2.6 \pm \quad .8$ & $16.6 \pm 2.2 *$ & $17.0 \pm 4.1 *$ & $2.3 \pm .4$ & $18.2 \pm .8^{*}$ & $21.2 \pm 3.2^{*}$ & $2.0 \pm .3$ \\
\hline
\end{tabular}

*Differed from the controls at least at the .05 level.

Hippocampally lesioned group. This group was severely impaired in detour problem-solving behavior in terms of performance on both Trial 1 and Trials 2-5. With respect to Trial $1,50 \%$ of the animals needed assistance on Problem A, $70 \%$ on Problem B, and $70 \%$ on Problem C. Of even greater interest, $30 \%$ needed assistance on at least three of the five trials on Problem A, $30 \%$ on Problem B, and $40 \%$ on Problem C.

These hippocampally damaged rats were significantly inferior to every one of the cortically damaged groups in terms of pooled errors on Trial 1 (ps $<.01$ ) as well as on Trials $2-5$ (ps $<.01$ ). Figure 4 further shows that the learning curves of Group $H$ were markedly separated from those of the cortically damaged groups.

\section{Latency Scores}

In an effort to provide some objective measure of motivation, time elapsing between the raising of the

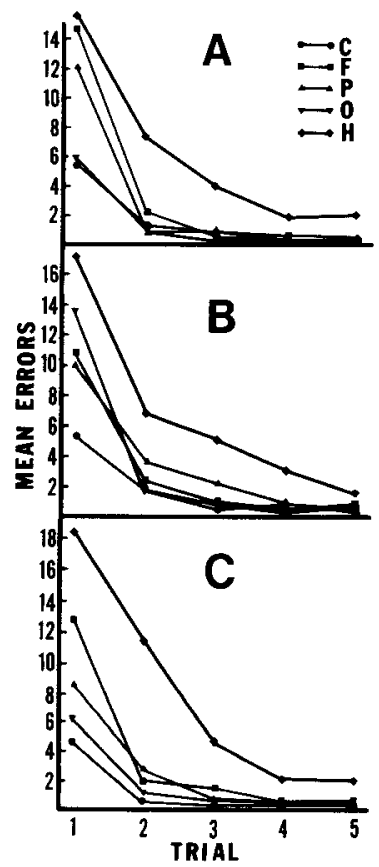

Figure 4. Mean errors on Problems A, B, and C for all groups. startbox door and entrance into the choice chamber was recorded on every trial. As shown in Table 1, none of the group differences in mean latency scores was found to be significant for Problem A. However, Group O on Problem B and Groups F and P on Problem $\mathrm{C}$ exhibited significantly longer latency scores than did the controls.

On the whole, latency scores did not correlate with individual error scores. With respect to the controls, the rank-order correlations between mean latency scores and pooled errors on Problems A, B, and C were $+.58,+.52$, and +.38 , respectively, none of which reached statistical significance. For Group H, the correlations, which were likewise insignificant, were +.44 (Problem A), +.22 (Problem B), and +.07 (Problem C). For all 31 cortically damaged rats, the correlations were +.25 (Problem A), -.15 (Problem $B$ ), and +.50 (Problem $C$ ); only the latter was significant $(\mathrm{p}<.02)$.

\section{Behavior in the Choice Chamber}

One of the striking differences in behavior between the brain-damaged rats (particularly those with frontal, parietal, and hippocampal lesions) and the controls on Trial 1 was that the latter tended to make initial contact (sniffing, touching with forepaws, or mounting) with the significant parts of the problem situation (leading edge of the platform on Problem A, rim of the cylinder on Problem B, and rungs of the ladder on Problem C) sooner than did the former. When confronted with the blocked pathway to the goalbox, the typical brain-damaged rat would repeatedly run back (toward the startbox) and forth (toward the goalbox) or would run from one corner to the next, continually circling the perimeter of the choice chamber without responding to the significant parts of the newly inserted detour. The controls, on the other hand, would ordinarily make initial contact with these parts after one or two back-and-forth excursions (or circles) in the choice chamber. A second striking difference was related to the persistence and variability of reactions to the significant parts of the problem situation. When the brain-damaged animals contacted these parts, their reactions were momentary and lacked the variability that characterized those 
of the controls. The controls, for example, spent more time investigating these parts, often making attempts to mount the elevated detour path. If these attempts were aborted, the controls would wander about the choice chamber for a short period of time, only to return to these significant parts for further exploration. The investigatory responses of the braindamaged animals, in contrast, were largely made up of sniffing and any attempt to mount, if it occurred at all, appeared only after many different visits to these parts.

\section{Activity and Rears}

Since the solution of the detour problems was conditional upon exploratory activity, it was deemed necessary to determine whether the brain-damaged animals of the current study differed from the controls in general activity. A rearing response was also considered relevant to the extent that it constituted both an orienting reaction to stimuli above eye level and a preparatory action to climbing. It will be seen in Table 2 that only Group $\mathrm{H}$ was significantly less active than the controls. (The relatively low score of Group $O$ was due mainly to the performance of three animals that entered fewer than 60 squares in the 10-min period.) Interestingly, Groups $F$ and $P$ made significantly more rears than Groups $\mathrm{C}$ or $\mathrm{O}$. None of the other differences reached statistical significance.

\section{DISCUSSION}

\section{Performance on Trial 1}

\section{A Measure of Response Flexibility}

It would appear that young rats with circumscribed lesions to the frontal (motor) cortex, parietal cortex, or dorsal hippocampus show a marked decrement in response flexibility - the readiness to abandon unsuccessful responses and to attempt new ones, until the correct one is found. This conclusion is based on the findings that these groups that sustained damage to these brain regions committed significantly more errors than the controls before discovering the correct path on each of the three detour problems. It is important to note that nonspecific effects arising from brain damage cannot readily account for these

Table 2

Open-Field Activity Scores for All Groups

\begin{tabular}{ccc}
\hline Group & $\begin{array}{c}\text { Number of } \\
\text { Squares Entered }\end{array}$ & $\begin{array}{c}\text { Number of } \\
\text { Rears }\end{array}$ \\
\hline C & $160.8 \pm 12.8$ & $21.2 \pm 5.3$ \\
F & $151.8 \pm 14.5$ & $36.8 \pm 4.5^{*}$ \\
P & $166.8 \pm 13.4$ & $35.5 \pm 3.8^{*}$ \\
O & $118.0 \pm 21.9$ & $17.4 \pm 3.4$ \\
H & $103.3 \pm 28.0^{*}$ & $28.0 \pm 6.4$ \\
\hline
\end{tabular}

*Differed from the controls at at least the 05 lev'el. findings inasmuch as the group with occipital lesions earned excellent performance scores on two of the three problems. (We have recently acquired data indicating that damage to the lateral brainstem at pontomesencephalic levels or pyramidal tract section fails to impair performance on any one of the three detour problems; Thompson, Harmon, \& Yu, 1984.)

It is also important to note that these findings are difficult to explain in terms of a motor disturbance because of the following observations: (1) None of our brain-damaged rats exhibited a locomotor deficit involving the forelimbs or hindlimbs, either during the detour tests or during the open-field test; (2) on Trials 2-5, most of our brain-damaged animals were virtually indistinguishable from the controls in their ability to perform the particular climbing response required on each problem; (3) the presence of a motor disturbance would lead to the expectation that performance on Trials 2-5 of Problem A (with respect to vertical distance between supporting surfaces, the climbing response required of Problem $\mathbf{A}$ is more difficult to execute than that required of Problem B or Problem C) would be impaired, yet Groups F and $P$ did not make significantly more errors on these trials than did the controls; (4) the postural response preparatory to climbing is a rear, and, as shown in the open-field test, Groups $\mathrm{F}, \mathrm{P}$, and $\mathrm{H}$ tended to make more rears than did the controls; and finally (5) young rats prepared with lesions to the lateral brainstem at pontomesencephalic levels were not deficient in solving Problem A despite the presence of a locomotor deficit (Thompson, Ramsay, \& Yu, 1984).

Although neocortical and hippocampal injuries were predicted to impair detour problem-solving behavior for the reasons mentioned at the outset of this paper, the severity of the impairment following the latter was entirely unexpected. Our hippocampally damaged rats made significantly more pooled errors on Trial 1 than did those rats with frontal, parietal, or occipital ablations. Furthermore, although only 2 of the 11 animals in Group F, 1 of the 10 in Group P, and none of the 10 in Group $O$ needed assistance on Trial 1 on at least two problems, 7 of the 10 animals in Group $\mathrm{H}$ did, and each of these differences, according to the Fisher exact probability test, is significant at least at the .05 level.

On the whole, these findings are in agreement with earlier observations suggesting that variability of responses is significantly diminished following injuries to either the neocortex or the hippocampus. In a Dashiell maze, for example, rats with various neocortical (Krechevsky, 1937a) or hippocampal (Niki, 1966) lesions were found to be less flexible in choosing different paths than were the controls. Similar findings have been reported in other maze-type situations (Hirsh, 1970; Krechevsky, 1937b, 1938; Niki, 1966). 
In contrast to earlier findings (Krechevsky, 1937a, 1937b, 1938; Lashley, 1935), however, our data do not indicate that response flexibility is appreciably compromised by occipital ablations. Although the animals of Group O performed poorly on Trial 1 of Problem B, a result that probably was due to a visual defect, they were able to find the correct detour path on Problems A and C about as efficiently as the controls. Hirsh (1970) and Niki (1966) have likewise failed to demonstrate that occipitally damaged rats are deficient in variability of responses, as gauged by performance on a four-choice task and a Dashiell maze, respectively. One likely explanation for these conflicting findings may lie in the fact that the early Krechevsky and Lashley studies contained a number of animals with occipital lesions that invaded significant portions of the parietal cortex; as a consequence of these cases with overlapping damage, the presence of a localized cortical effect on the problems investigated might have been obscured.

\section{Nature of the Deficit}

Rats with hippocampal or neocortical lesions have been characterized, at one time or another, as showing a disturbance in response inhibition (Douglas, 1967; Gray, 1982; Thompson, 1978b), recent ("working”') memory (Lashley, 1929; Olton \& Papas, 1979), behavioral exploration (Lashley, 1935; O'Keefe \& Nadel, 1978), and/or attention (Lashley, 1935; Oades, 1982). Any one of these disturbances could underlie the reduction in response flexibility reported in the current experiment. This is evident from observations of the behavior of those rats composing Groups $\mathrm{F}, \mathrm{P}$, and $\mathrm{H}$ : they tended to commit more perseverative errors (revisits to the partition between the choice chamber and goalbox) than the controls before making contact with the significant parts of the problem situation (suggesting a loss in response inhibition or working memory) and, once contact was made, did not show the persistent responsiveness and variable reactions to these parts that characterized the behavior of the controls (suggesting a loss in behavioral exploration or attention).

It is equally difficult to determine whether the nature of the deficit in response flexibility induced by hippocampal lesions is different from that induced by neocortical lesions, since each of the groups with frontal, parietal, and hippocampal damage was deficient on Trial 1 of all three problems. According to the theories (Gray, 1982; O'Keefe \& Nadel, 1978; Olton, 1978; Vinogradova, 1975) that attribute some kind of "comparator" role to the hippocampal formation (comparing actual with stored information), the nature of the deficit associated with hippocampal lesions would be expected to bear some resemblance to that associated with neocortical lesions. This would follow from the fact that the latter would also disrupt hippocampal function to the extent that the hippo- campus would be deprived of certain kinds of sensory input necessary to transact its comparator role. This account would seem to explain the similar disturbances observed in neocortically and hippocampally damaged rats on such tasks as complex mazes (Foreman \& Stevens, 1982; Thompson, 1979), position reversals (Thompson, 1983), and active and passive avoidance responses (Thompson, 1978b).

However, it must be recognized that neocortical lesions produce impairments on maze, position reversal, and active and passive avoidance responses that cannot be satisfactorily explained in terms of sensory privation (Dale \& Goodale, 1979; Lashley, 1929; Thompson, 1979, 1982, 1983). These data would suggest that the role of the hippocampus in behaviors that are disorganized by neocortical lesions may not necessarily be dependent upon sensory information from the neocortical receiving areas. As pointed out earlier (Thompson, 1982), a better understanding of the contrasting functions of the neocortex and hippocampus in learning and memory (and response flexibility) will be achieved when more investigators decide to examine concurrently the contributions of these two neural formations in the performance of various laboratory tasks.

\section{Performance on Trials 2-5: A Measure of Detour Habit Formation}

Although the groups with frontal, parietal, and hippocampal lesions displayed similar impairments on Trial 1 of each problem, a different pattern of results emerged in connection with performance on Trials 2-5. As shown in Figure 4, hippocampal damage induced a dramatic impairment on Trials 2-5 on every problem. Neocortical damage, in contrast, yielded more variable effects, either failing to induce an impairment on these trials or inducing a mild impairment. Specific instances of a dissociation between performance on Trial 1 (error scores were significantly greater than those of the controls) and that on Trials 2-5 (error scores were not significantly greater than those of the controls) were observed in Group $F$ on Problems A and B, Group P on Problem A, and Group $\mathrm{O}$ on Problem $\mathrm{B}$. These findings suggest that hippocampal lesions interfere with the formation of detour habits to a greater extent than do neocortical lesions. They further suggest that the nature of the deficit seen on Trials $2-5$ is different from that seen on Trial 1.

It is clear that the learning deficits observed in Group $\mathrm{H}$ are most readily explicable in terms of the O'Keefe and Nadel (1978) theory concerning the role of the hippocampus in place learning. Our detour problems can be viewed as simple spatial mazes with a true path and a "blind alley." Since salient intramaze cues were not available to distinguish the true path from the blind alley, intertrial improvement on 
such tasks would be facilitated by the engagement of a place learning mechanism.

It was somewhat surprising, however, that our neocortical lesions (particularly those involving the parietal and occipital areas) did not interfere with the acquisition of all three detour problems. Rats with similarly localized cortical lesions are known to be deficient in place learning, as gauged by performance on simple (Lashley, 1929; Thompson, 1983) and complex (Lashley, 1929; Thomas \& Weir, 1975; Thompson, 1979) maze habits. Furthermore, an extensive series of experiments comparing the effects of occipital lesions with those of hippocampal lesions on a wide variety of laboratory tasks led to the conclusion that the nonvisual function of the former was closely associated with the spatial functions of the latter (Thompson, 1982), a conclusion that must be revised in light of the present findings. Again, the question must be raised concerning the extent to which the neocortical areas are functionally related to the hippocampus. Such a relationship undoubtedly exists, but it is likely to be more complex than currently conceived.

\section{Conclusions}

"Climbing" detour problems would appear to be sensitive to lesion-induced alterations in response flexibility. It should be noted, however, that other types of detour problems may not yield a pattern of results like those reported in the present experiment. In our pilot studies, for example, a problem requiring the displacement of a centrally located hinged door or one involving the tearing through of a centrally located perforated paper window did not distinguish hippocampally or neocortically damaged rats from the controls in terms of errors committed on Trial 1. The reason for this is uncertain, but it may have been due to the presence of transfer effects from preliminary training in the case of the doordisplacement problem and the presence of olfactory cues in the case of the paper window problem.

Detour problem-solving behavior was originally viewed as "insightful"' (Köhler, 1927) and involving "creative ideation"' (Tolman, 1932), but can also be interpreted within a behavioristic framework as accessing a response that, for a given situation, is low on the habit-family hierarchy (Hull, 1952). Whether or not the detour problem imposes a demand on reasoning, it does seem to tap a cognitive function that is qualitatively different from that underlying simple associative learning. This was shown by the neocortically injured groups whose performance on Trial 1 was inferior to that of the controls, but whose performance on Trials 2-5 closely matched that of the controls. These findings can be interpreted as supporting Lashley's (1935) contention that cerebral lesions, rather than interfering with an associative mechanism, tend to disorganize functions related to exploration, attention, insight, and initiative. A similar view has recently been articulated by Oakley (1981).

\section{REFERENCES}

Dale, R. H. I., \& Goodale, M. A. (1979). Effect of visual cortex lesions on radial maze performance in rats. Society for Neuroscience Abstracts, 5, 114.

Douglas, R. J. (1967). The hippocampus and behavior. Psychological Bulletin, 67, 416-442.

Foreman, N., \& Stevens, R. (1982). Visual lesions and radial maze performance in rats. Behavioral and Neural Biology, 36, 126-136.

Gray, J. A. (1982). The neuropsychology of anxiety. New York: Oxford University Press.

HIRSH, R. (1970). Lack of variability or perseveration: Describing the effect of hippocampal ablation. Physiology \& Behavior, 5, 1249-1254.

Hull, C. L. (1952). A behavior system. New York: Wiley.

KöHLER, W. (1927). The mentality of apes. New York: Vintage.

KRECHevsKY, I. (1937a). Brain mechanisms and variability. I. Variability within a means-end-readiness. Journal of Comparative Psychology, 23, 121-138.

KRECHEvSKY, I. (1937b). Brain mechanisms and variability. III. Limitations of the effect of cortical injury upon variability. Journal of Comparative Psychology, 23, 351-364.

KRECHEVSKY, I. (1938). Brain mechanisms and umweg behavior. Journal of Comparative Psychology, 25, 147-174.

LASHLEY, K. S. (1929). Brain mechanisms and intelligence. Chicago: University of Chicago Press.

LASHLEY, K. S. (1935). Studies of cerebral function in learning. XI. The behavior of the rat in latch box situations. Comparative Psychological Monographs, 11, 5-42.

Niki, H. (1966). Response perseveration following the hippocampal ablation in the rat. Japanese Psychological Research, 8, 1-9.

OAdES, R. D. (1982). Attention and schizophrenia. Boston: Pitman.

OAKLEY, D. A. (1981). Brain mechanisms of mammalian memory. British Medical Bulletin, 37, 175-180.

O'KeEFE, J., \& NADEL, L. (1978). The hippocampus as a cognitive map. Oxford: Clarendon Press.

Outon, D. S. (1978). Characteristics of spatial memory. In S. H. Hulse, H. Fowler, \& W. K. Honig (Eds.), Cognitive processes in animal behavior (pp. 341-373). Hillsdale, NJ: Erlbaum.

Olton, D. S., \& Papas, B. C. (1979). Spatial memory and hippocampal function. Neuropsychologia, 17, 669-682.

Riopelle, A. J. (1967). Animal problem solving. Baltimore: Penguin.

Thomas, R. K., \& WEIR, V. K. (1975). The effects of lesions in the frontal or parietal association cortex of rats on maze III. Physiological Psychology, 3, 210-214.

Thompson, R. (1978a). A behavioral atlas of the rat brain. New York: Oxford University Press.

Tномpson, R. (1978b). Localization of a "passive avoidance memory system" in the white rat. Physiological Psychology, 6, 263-274.

Thompson, R. (1979). Hippocampal and cortical function in a maze devoid of left and right turns. Physiology \& Behavior, 23, 601-603.

Thompson, R. (1982). Evidence that the occipital cortex also functions in place learning in rats. In C. Ajmone Marsan \& $\mathrm{H}$. Matthies (Eds.), Neural plasticity and memory formation (pp. 453-463). New York: Raven Press.

Thompson, R. (1983). Abnormal learning and forgetting of individual spatial reversal problems in brain-damaged rats. Physiological Psychology, 11, 35.46. 
Thompson, R., Harmon, D., \& Yu, J. (1984). Detour problemsolving behavior in rats with early lesions to the "general learning system. "Unpublished manuscript.

Thom PSON, R., Ramsay, A., \& Yu, J. (1984). A generalized learning deficit in albino rats with early median raphe or pontine reticular formation lesions. Physiology \& Behavior, 32, 107-114. Tolman, E. C. (1932). Purposive behavior in animals and men. New York: Century.
Vinogradova, O. S. (1975). Functional organization of the limbic system in the process of registration of information: Facts and hypotheses. In R. L. Isaacson \& K. H. Pribram (Eds.), The hippocampus (Vol. 2). Neurophysiology and behavior (pp. 1-70). New York: Plenum Press.

(Manuscript received March 15, 1984; revision accepted for publication May 25, 1984.) 